thus shifting emphasis from results about summation processes for divergent series to a more general theory of transforms. Since then the theory has branched out in several directions, and a comprehensive treatise would be voluminous. But along the main lines laid down by Hardy-Littlewood and Wiener, simplifications and generalizations have been made by many workers, among whom Prof. Pitt has been prominent.

He has now organized this material into a single short volume, the second in the series of monographs on advanced topies sponsored by the Tata Research Institute of Bombay. It is a book for the professional mathematician contemplating work in this field, and a fair degree of sophistication is needed to follow the clear but very concise reasoning. There are chapters on the Hardy-Littlewood and Wiener theorems, and one on theorems developed from Mercer's result (1907), that if $\sigma_{n}$ is the mean of $s_{1}, \ldots, s_{n}$, and $\alpha>0$, the convergence of $\alpha s_{n}+(1-\alpha) \sigma_{n}$ implies the convergence of $s_{n}$; this has the remarkable air of being a Tauberian theorem without a Tauberian condition. Finally, there is a chapter on the prime number theorem; here it appears essential to work with means related to the primes, so that Tauberian theorems are obviously relevant. But Pitt points out that neither the Ikehara-Landau proof, perhaps the simplest, nor the recent SelbergErdös proof, certainly the most elementary since it demands no knowledge of Riemann's $\zeta$-function, uses Wiener-type Tauberian theorems, and he offers some pointers towards a study of general Tauberian theorems which are not of Wiener's type. If this prompts some young research worker to investigate the topic, the author and the Tata Institute should be gratified.

T. A. A. BroAdBent

\section{MAGNETIC AMPLIFIERS}

The Theory and Design of Magnetic Amplifiers By Dr. E. H. Frost-Smith. (Automation and Control Engineering Series.) Pp. xix +487 . (London : Chapman and Hall, Ltd., 1958.) 75s. net.

T HIS well-written and comprehensive book can be recommended to both students and professional engineers, and many will wish that it had appeared earlier.

The introductory chapter is noteworthy for the emphasis which it puts on mean rectified values of voltages and currents in terms of which transductor characteristics are conveniently described. Two chapters are then devoted to the principal parameters and characteristics, both steady-state and transient, of transductors with idealized core-materials. From this basis the theory of self-excited and auto-excited transductors with practical core-materials and imperfect rectifiers is developed and the influence of reactive loads is discussed.

A short chapter on the theory of control systems is included and a further treatment of the dynamic response of transductors with resistive and reactive loads is discussed in terms of control-system theory. This leads naturally to the need for quick-response transductors in control systems and an admirable chapter is devoted to half-wave, full-wave and threephase transductors having short-response times.

The three chapters which follow deal with balanced magnetic amplifiers, low-level signal amplification and cascaded amplifiers, and magnetic modulators.
The section on design summarizes the properties of core-materials and their influence on transductor characteristics. A design procedure is developed and is illustrated by three examples, one of which extends to the overall performance of a magnetic-amplifier position-servo. The mixture of units with which engineers still have to deal, despite the adoption of the M.K.s. system for basic equations, is apparent in this chapter.

The final chapter on applications covers a wide field and leaves no doubt as to utility of transductors.

Most chapters have concluding summaries and these, together with the list of references to original papers, make this book a valuable acquisition for engineers entering this field. J. G. HENDERSON

\section{TREES OF BRITAIN}

\section{Trees of Britain}

By Dr. Robert Gurney. Pp. $228+18$ plates. (London : Faber and Faber, Ltd., 1958.) 30s. net.

THE late Dr. Robert Gurney had wide biological interests and collected a great deal of information from his own painstaking observations over a period of many years, particularly around Oxford (his home) and in Norfolk. Trees were, perhaps, his primary interest in his later years, and an earlier book of his, "Our Trees and Woodlands" (Medici Society, 1947), will be known to many. The present volume possesses certain special features that are not to be found in the usual books dealing with trees in the British Isles. Most of the books that have appeared hitherto have dealt either with the native trees or with the introduced trees, grown for ornament or for timber. In the present volume Dr. Gurney deals with both these categories, covering all the common trees, wild or cultivated, that are to be found throughout the country. About one hundred different species are dealt with, each receiving separate treatment. The general information accompanying each description includes facts concerning the origin of each species, date of introduction to Britain (where known), general behaviour and growth characteristies. The clear line drawings that accompany each description are a notable feature of the book. They are the work of Dr. Gurney himself, and they usually include a drawing of the seedling, which the author raised from seed which he had himself collected. Another feature of the book is the emphasis that has been placed on buds or bud morphology, and bud development, the features brought to light being illustrated in the drawings. In addition to line drawings there are photographs showing individual trees or groups of trees in various parts of the British Isles. These are all pleasing or exceptional photographs of their kind and may well have been selected for their asthetic value.

In the section on "Conifers and their Allies", all the species yielding softwoods of importance in Britain or of use in other respects are described. A table giving the dates of introduction of coniferous trees to Britain is of interest. From this it appears European spruce (Picea abies) is the earliest introduction (1548), while Metasequoia glyplostroboides is the most recent (1948). It is of interest to note that two important conifers, Japanese larch (Larix leptolepis : introduced 1861) and western hemlock (Tsuga heterophylla: introduced 1863), have not yet been in cultivation for a hundred years in the British Isles. 